\title{
Using Color Full-Scale Schlieren (CFSS) technique to improve kitchen exhaust hood performance
}

\author{
Chung-Hwei Su${ }^{1}$, Chien-Chih Chen ${ }^{2}$, Li-Yu Yeh ${ }^{3}$, Yu-Cheng Hung ${ }^{4}$, Chen-Ching Ting 5, * \\ ${ }^{1}$ Department of Safety, Health and Environmental Engineering, National Kaohsiung First University of Science and Technology, Taiwan \\ ${ }^{2}$ Graduate Institute of Mechanical and Electrical Engineering, National Taipei University of Technology, Taipei, 10608 Taiwan \\ ${ }^{3}$ Institute of Mechatronic Engineering, National Taipei University of Technology, Taipei, 10608 Taiwan \\ ${ }^{4}$ Institute of Manufacturing Technology, National Taipei University of Technology, Taipei, 10608 Taiwan \\ ${ }^{5}$ Department of Mechanical Engineering, National Taipei University of Technology, Taipei, 10608 Taiwan
}

\section{Email address:}

such@nkfust.edu.tw (Chung-Hwei Su), t8669030@ntut.edu.tw (Chien-Chih Chen), frontmission104@hotmail.com (Li-Yu Yeh), joy77217@hotmail.com (Yu-Cheng Hung), chchting@ntut.edu.tw (Chen-Ching Ting)

\section{To cite this article:}

Chung-Hwei Su, Chien-Chih Chen, Li-Yu Yeh, Yu-Cheng Hung, Chen-Ching Ting. Using Color Full-Scale Schlieren (CFSS) Technique to Improve Kitchen Exhaust Hood Performance. American Journal of Optics and Photonics. Vol. 2, No. 2, 2014, pp. 18-23.

doi: $10.11648 /$ j.ajop.20140202.12

\begin{abstract}
This article uses color full-scale Schlieren for heat flow visualization of the kitchen exhaust hood. Using grease filters with same percentage of opening but different forms for measurements the heat flow escaping rate, noise, and air velocity of the kitchen exhaust hood under conditions of different percentage masking. The results show that using different grease filters without masking has no escaping heat flow. Employing the rectangular filter with side masking has the worst heat flow escaping. The top masking has also no heat flow escaping and the form with circular opening has the strongest absorbability. In this work, the smallest noise level is $65 \mathrm{~dB}$ which appears at the situation of top masking. Moreover, kitchen exhaust hood without masking the air flow rate increase $3.17 \%$ of the air velocity than side masking.
\end{abstract}

Keywords: Color Full-Scale Schlieren, Flow Visualization, Grease Filters

\section{Introduction}

Full-scale Schlieren technique was famous and especially developed for flow visualization with large area of test section. Neglecting three-dimensional effect, the full-scale Schlieren technique is suitable for flow visualizations of e.g. heating, ventilating, and air conditioning. It can directly and easily show heat flux distribution in a grand test size. In 1995, Settles et al. first presented the simple and large Schlieren optical system for qualitative visualization of the ventilation airflows, such as commercial kitchen griddle and exhaust hood, daily room, removing a frozen pizza, planar turbulent jet of heated air [1]. In 1999, Settles et al. further presented outdoor Schlieren and shadowgraph imaging, for visualization of outdoor thermal convection, combustion, and explosion phenomena, such as jet aircraft and high-speed flight [2].

In 2001, Settles et al. presented a very large Schlieren optical system with test section area of $2.3 \times 2.9 \mathrm{~m}^{2}$. The key element of the full-scale Schlieren system is the front illuminated source grid which is mounted by 12 pieces of aluminums sign panels that are assembled on a frame, where dimension of a single aluminum sign panel is $1.2 \mathrm{~m} \times 2.4 \mathrm{~m} \times$ $2.5 \mathrm{~mm}$. Upon the retroreflective material is silk-screened 5.08 $\mathrm{mm}$ wide vertical black grid lines spaced $5.08 \mathrm{~mm}$ apart. The author visualized many objects, such as heating and ventilation airflows, thermal plumes of people, aerodynamics of an explosive trace detection portal, gas leak detection, shock wave motion, and the discharge of firearms [3].

Full-scale Schlieren technique can be divided into two types in terms of different experimental arrangement. The one is retroreflective full-scale Schlieren which uses light projector to project penetration light through the test section on the retroreflection screen. The retroreflection screen shows first the shadowgraph image and the reflected light is focused through a condense lens on the camera. The most so far presented data in the references are captured by using the retroreflection method. The other one is backgroundoriented full-scale Schlieren which directly builds the background-oriented light source to project penetration light through the test section and be refocused through a convex lens on the camera. There are very few studies on the 
background-oriented full-scale Schlieren. In 2011, C. C. Ting and C. C. Chen studied the rate of cutoff grid effect on the sensitive of imaging. The applied cutoff grids are with 50, $60,70,80$, and $90 \%$ of the cutoff light percentage respectively. The test objects are burning candle, LPG flow ejecting into surrounding, and burning alcohol. The results show that the cutoff grid with $60 \%$ received the best flow visualization image [4 - 7].

In the research of the kitchen exhaust hood, present study focused on noise and heat flux of the kitchen exhaust hood. For the users who working in the kitchen, long - term inhalation the cooking smell will harm their body. Although setting kitchen exhaust hood can solve the cooking smell problem, it also bring noise problem too. Generally speaking, kitchen exhaust hood produces the sound when operating is low - frequency noise which is easy to affect the user's mood, so that users feel impatient and cause pressure. In addition, the low - frequency noise would affect to sleep and psychology, it may lead to neurasthenia or depression and other symptoms. Briefly speaking, long-term exposure to the environment with noise would harm the human body. In 2000, Chiang et al. investigated flow fields, temperature fields, and air contaminant of kitchen hood at indoor air environment by using numerical simulations [8]. Five years later, In 2005, Abanto et al. analyzed the number of blades and the twisting angle of kitchen hood system performance by using Computational Fluid Dynamics at operating conditions[9]. There are some articles focused on reducing noise by optical method or translation the noise to power energy[10-11]. In 2014, Young et al. using micro color Schlieren technique to visualize compressed diamond flow of nozzle[12].

Duct and motor are two major configurations of kitchen exhaust hood. Presently, noise values are between 60 and $80 \mathrm{~dB}$ which obtained at a distance from opening about 20 $\mathrm{cm}$ and most of kitchen exhaust hoods can reach the standards set by CNS [13-14]. After using kitchen exhaust hoods for a while the noise is usually greater than $70 \mathrm{DB}$ and $69 \mathrm{~dB}$ low - frequency noise will make users feel uncomfortable. Based on above discussion the kitchen exhaust hoods still have some deficiencies which can be improved. Since using optical methods to visualization and improving heat flux of the kitchen exhaust hood is more directly, this paper make use of color full - scale Schlieren to visualize heat flux of the kitchen exhaust hood and discuss heat flux flowing situation with different grease filters and various masking conditions.

Full-scale Schlieren technique is a famous and especially developed for flow visualization with large area of test section. This work uses the optimal sensitive parameter of previous study to visualize the heat flow of the kitchen exhaust hood and observe the heat flux distribution.

\section{Basic Theory}

Full - scale Schlieren which make use of the light passing through the test section and imaging by penetrating through the convex lens is a convenient technique for optical visualization. Figure 1 shows schematic of the focusing Schlieren system. In addition, calculated the full - scale Schlieren sensitivity $\varepsilon_{\min }$, the Weinstein's contribution model was be used [3] as shown in the following figure.

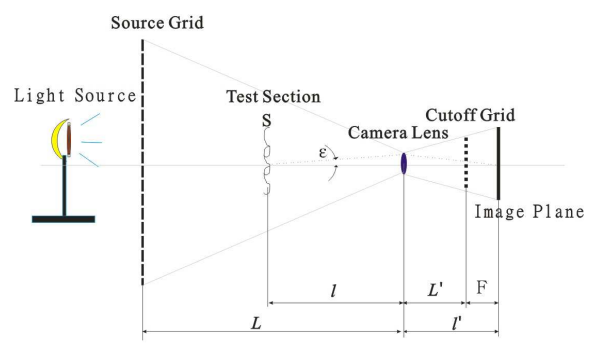

Figure 1. Schematics of the focusing Schlieren system

$$
\begin{aligned}
\varepsilon_{\min } & =\frac{2}{k} \frac{\Delta E}{E} \frac{L}{L^{\prime}(\mathrm{L}-1)} \\
& =a \frac{\Delta E}{E} \frac{L}{L^{\prime}(\mathrm{L}-1)} \quad \text { (radians) }
\end{aligned}
$$

Where $\mathrm{k}$ is a number of line-pairs per millimeter and $\Delta \mathrm{E} / \mathrm{E}=0.1$ is a $10 \%$ detection threshold. Equation (1) can therefore be rewritten as follow:

$$
\varepsilon_{\min }=20626 a \frac{L}{L^{\prime}(\mathrm{L}-1)} \quad \text { (arcseconds) }
$$

Where 1 radian $=20625$ arcseconds.

The parts of knife - edge and source grid can be as the imaging of objects with lines width, then imaging on the cutoff grid by the light passing through the convex lens. By means of the geometrical optics, the distance between cutoff grid and lens can be calculated and then derive the scale to get the size and position of the image on cutoff grid. If the lines width of the cutoff grid is $b$, then the distance between brightness width and darkness width can be derived from different cutoff rate. That is, brightness width is $b-(b \times$ cutoff-rate $)$ and darkness width is $b+(b \times$ cutoff-rate). Table 1 shows the distance to different cutoff grids.

Table 1. Band distances of the cutoff grid

\begin{tabular}{ccccc}
\hline \multicolumn{5}{c}{ Focal length, $\mathbf{f}=\mathbf{5 0 1 . 3} \mathbf{~ \mathbf { m }}$, Band width, $\mathbf{b}=\mathbf{0 . 5 4 6} \mathbf{~ m m}, \mathbf{L}=\mathbf{6 m}, \mathbf{l}=\mathbf{3 m}$} \\
\hline Brightness width $(\mathrm{mm})$ & 0.273 & 0.218 & 0.163 & 0.109 \\
Darkness width $(\mathrm{mm})$ & 0.819 & 0.874 & 0.929 & 0.983 \\
Cutoff rate $(\%)$ & 50 & 60 & 70 & 80 \\
\hline
\end{tabular}

In this study, assuming the cavity is infinite, so that the cavity can be considered as a constant pressure situation. The leakage of gas flowing through the heat exchanger and after a period of time, the temperature of gas will be equal to the ambient temperature. According to Bernoulli's law:

$$
p_{1}+\frac{1}{2} \rho v_{1}^{2}+\gamma z_{1}=p_{2}+\frac{1}{2} \rho v_{2}^{2}+\gamma z_{2}
$$


Assuming that $\mathrm{z} 1=\mathrm{z} 2, \mathrm{v} 1=0$ and $\mathrm{p} 2=0$, then the fluid velocity of outlet as shown below:

$$
v_{2}=\sqrt{\frac{2 p_{1}}{\rho}}
$$

When applied $\mathrm{v} 2(\mathrm{~m} / \mathrm{s}) \times \mathrm{A} 2$, then can get the leakage rate $\mathrm{Q}(\mathrm{m} 3 / \mathrm{s})$ as shown below:

$$
Q=A_{2} v_{2}
$$

This work uses homemade Pitot tubes with $U$-shaped tubes to measure the wind velocity. The homemade Pitot tube is combined with two tubes, inner tube and outer tube. The inner tube which opening faces the fluid direction is used as stagnant tube. The outer tube has a small opening can connect to side tube. The fluid speed can be derived from the pressure difference between inner and outer tube as shown in Fig. 2. Assuming that the tip of Pitot tube as the stagnant point, the fluid speed is equal to zero and flow field is unaffected by Pitot tube. That is, $\mathrm{p} 1=\mathrm{p} 2$, due to point 1 and point 2 have same height, then $\mathrm{z} 1=\mathrm{z} 2$. According to Bernoulli's law from equation (3), v1 can be written as follow:

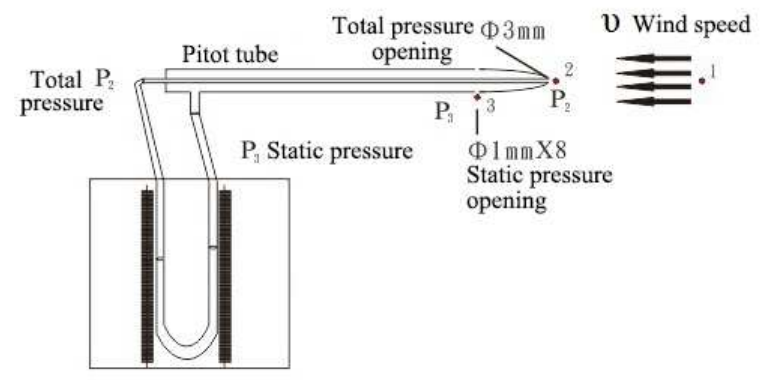

Figure 2. Schematics of the air velocity and wind speed measurement

$$
v_{1}=\sqrt{\frac{2 \Delta p}{\rho}}
$$

Where $\Delta \mathrm{p}$ is defined as pressure difference and $\gamma \mathrm{w}$ is defined as liquid specific gravity and $\Delta \mathrm{h}$ is defined as the height difference of the liquid in the $U$ - shaped tube. The air velocity $\mathrm{Q}$ can be obtained by the cross - section area multiplying wind speed. Thus, Q can be written as follow:

$$
\begin{aligned}
& \Delta p=\gamma_{w} \Delta h \\
& Q=60 \pi r^{2} v
\end{aligned}
$$

\section{Experimental Setup}

This study uses 28 full spectrum fluorescent lamps (Philips-865) as the matrix light source for the measurements. These lamps separate equally each other and its light source section is $2 \times 2 \mathrm{~m}^{2}$. When light passing through the atomizing film, it will be scattered the propagation direction and then pass through the color mask, finally the light focusing by convex lens and receiving by CCD camera. Fig. 3 shows photo of the background-oriented light source detail setup. Fig. 4 exhibits photo of the source grid with color light source. Fig. 5 shows the spectrum distribution of the fluorescent lamps.

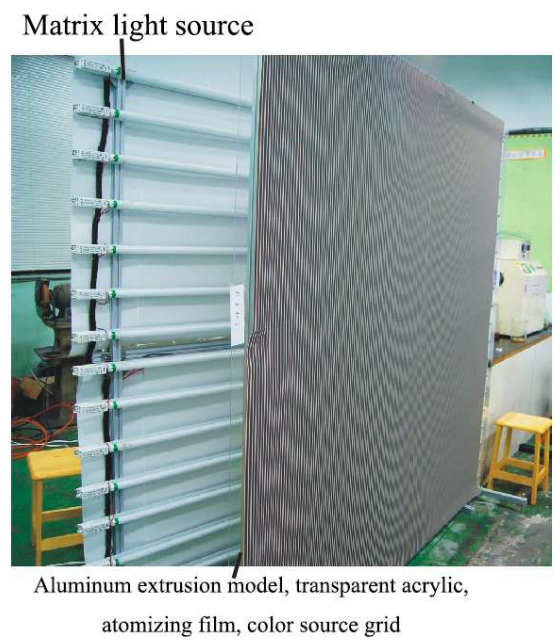

Figure 3. Setup photo of the background-oriented light source

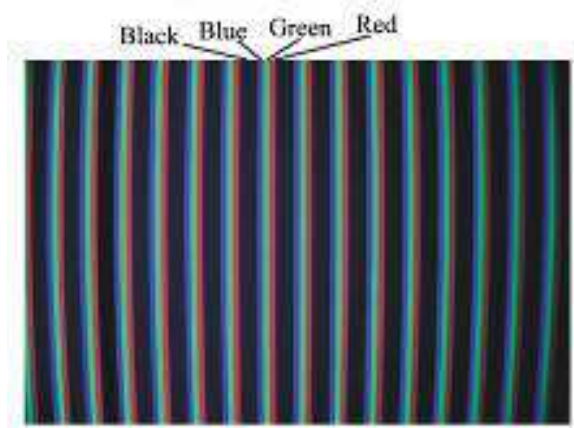

Figure 4. Source grid with color light source

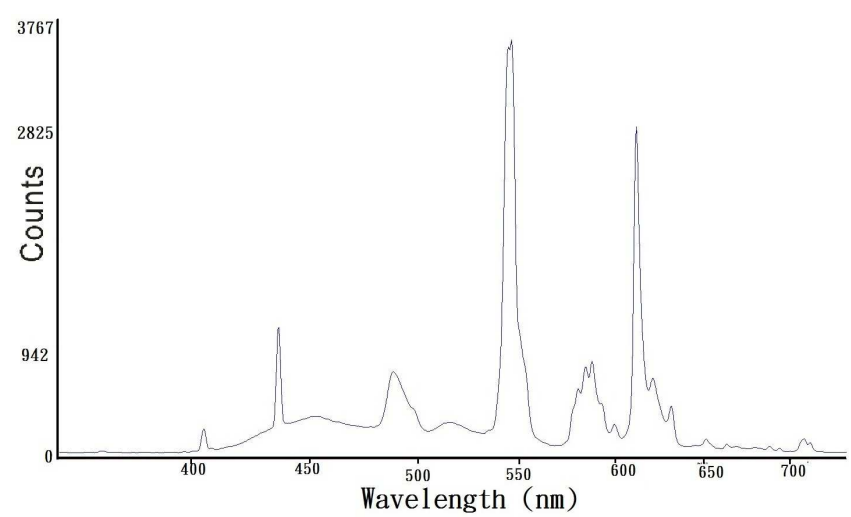

Figure 5. Spectrum distribution of the fluorescent lamps

Color full-scale Schlieren system is composed of background-oriented light source and photographical room. The photographical room is built for the photographical purpose and it is made up by condense lens, the cutoff grid, image plane, and the CCD camera. Fig. 6 shows setup photo of photographical room. 


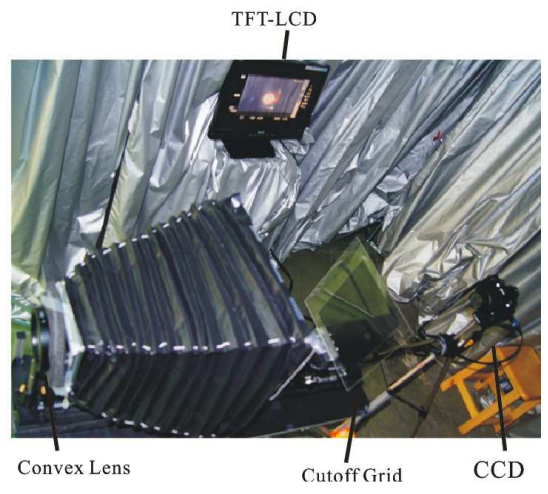

Figure 6. Setup photo of photographical room

Due to find the influence of noise and exhaust on the kitchen exhaust hood, this study using filters and support frame setting up the kitchen exhaust hood then cutting openings on top filter and side filter. Fig. 7 shows setup photo of the testing kitchen exhaust hood. On grease filters side, Fig. 8 shows photo of different type grease filters, type1 grease filters using diameter with $4 \mathrm{~cm}$ circular openings, type 2 using $2 \times 23 \mathrm{~cm}$ rectangular openings, and type 3 using $69 \mathrm{~cm} 2$ trapezoid openings. All of the openings have same percentage of the aperture rate. Furthermore, this work uses burning candles as heat source which its fumes is used to simulate the cooking smell.

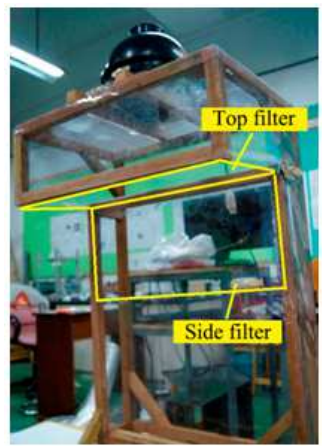

Figure 7. Experimental setup photo of the testing kitchen exhaust hood

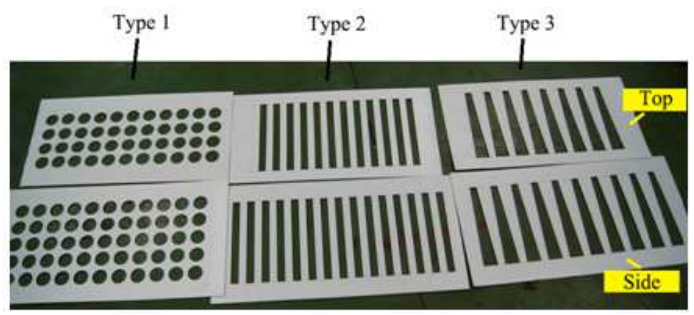

Figure 8. Three different type grease filters

The experimental setup detail of noise measurement is based on the standards of Chinese National Standard (CNS) 3805 and 3765-31 as shown in figure 9. The setup of air velocity measurement is based on the standards of American Society for Testing and Materials (ASTM) D3154-00 [15]. Each Pitot tubes total length is $1 \mathrm{~m}$. The diameter of the total pressure opening is $3 \mathrm{~mm}$ and the diameter of the static pressure openings is $1 \mathrm{~mm}$. Fig. 10 shows the setup of the air velocity measurement.
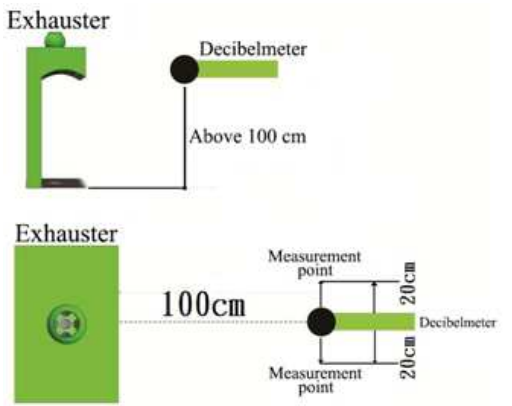

Figure 9. Schematics of the noise measurement

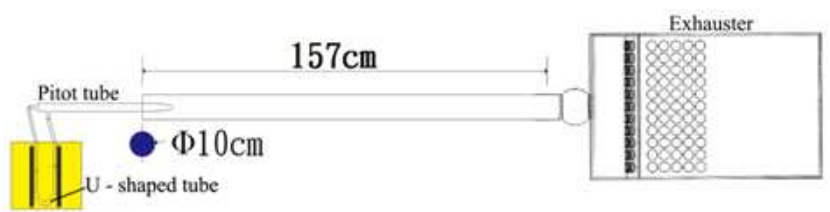

Figure 10. Schematics of the air velocity measurement

\section{Results and Discussion}

This study discusses the influence of different cutoff rate on color full-scale Schlieren system. For obtaining more colorful effect and more sensitivity during different various refraction index field of the image, we divide the source grid into transparent part and non-transparent part. The transparent part composed by three equal segments and print three primary colors, R, G, and B serving as red, green, and blue which are the basic color components of visible white light. Fig. 11 shows color full-scale Schlieren image photo of turning on stove to generate heat flow. Figs. 11(a) - (d) show photos of cutoff grid under 50, 60,70, and $80 \%$ cutoff rate respectively. The results show that the Fig. (b) has the best sensitivity, namely, full-scale Schlieren with $60 \%$ cutoff rate could be used in further study.
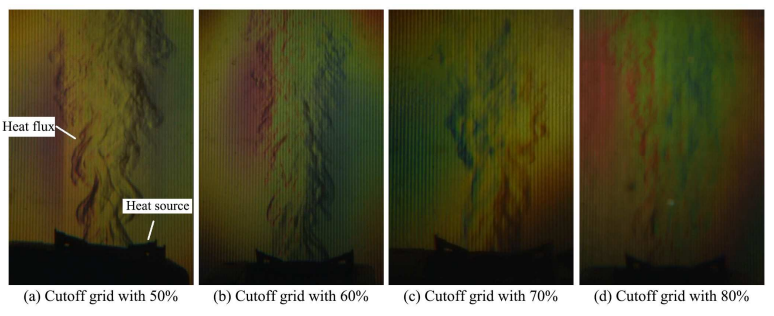

Figure 11. Cutoff grid with various cutoff rates

In this work, the color full-scale Schlieren experimental setup bases on the optimal conditions from previous discussion. That is, this work uses light band width $6 \mathrm{~mm}$ of source grid and cutoff rate under $60 \%$ which is used for observing the heat flow of the kitchen exhaust hood with different type grease filters. All of the grease filters have same open holes rate but different shapes. Fig. 12 shows photo of heat flow visualization with different type grease filters, namely, the gas inlet located at top and side of kitchen exhaust hood are open. Fig. 13 shows photo of heat 
flow behavior under blocking side inlet and puts grease filters on top inlet of kitchen exhaust hood. Fig. 14 shows photo of heat flow performance under blocking top inlet and puts grease filters on side inlet of kitchen exhaust hood.

Fig. 12 shows photo of kitchen exhaust hood heat flow with different type grease filters by using color full-scale Schlieren technique. Fig. 12(a) shows photo of heat flow visualization with type 1 grease filter. Fig. 12(b) shows photo of heat flow behavior with type 2 grease filter and fig. 12(c) shows photo of heat flow behavior with type 3 grease filter. The results show that there has no heat flow escaping by kitchen exhaust hood. All waste gas with poison could be captured.

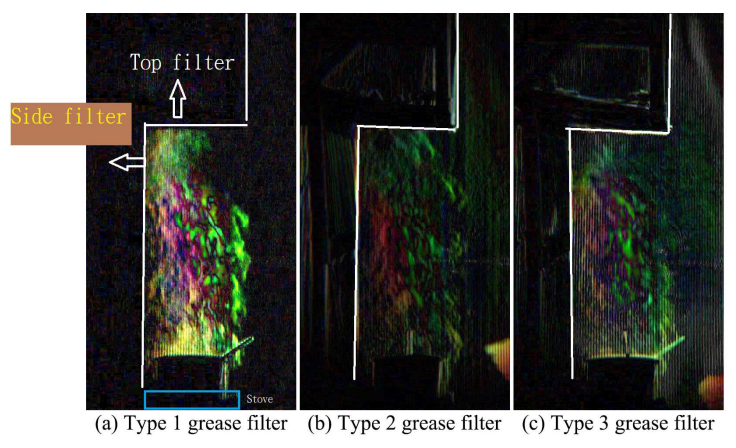

Figure 12. Photo of heat flow without any blockage

Fig. 13 shows photo of heat flow behavior under blocking side inlet and puts grease filters on top inlet of kitchen exhaust hood by using color full-scale Schlieren method. Fig. 13(a) shows photo of heat flow distribution with type 1 grease filter. Fig. 13(b) shows photo of heat flow behavior with type 2 grease filter. Fig. 13(c) shows photo of heat flow performance with type 3 grease filter. The results show that the heat flow can't be completely captured by kitchen exhaust hood with three type of grease filters. Fig. 13(a) shows the best capturing performance of kitchen exhaust hood in fig. 13. As the fig. 13 shows that the escaping waste gas of heat flow in fig. 12(a) is less than fig. 12(b), and the escaping waste gas of heat flow in fig. 12 (c) is also less than fig. 12(b). Namely, type 1 grease filter under block side inlet and puts grease filters on top inlet of kitchen exhaust hood by using color full-scale Schlieren technique owns the best result.
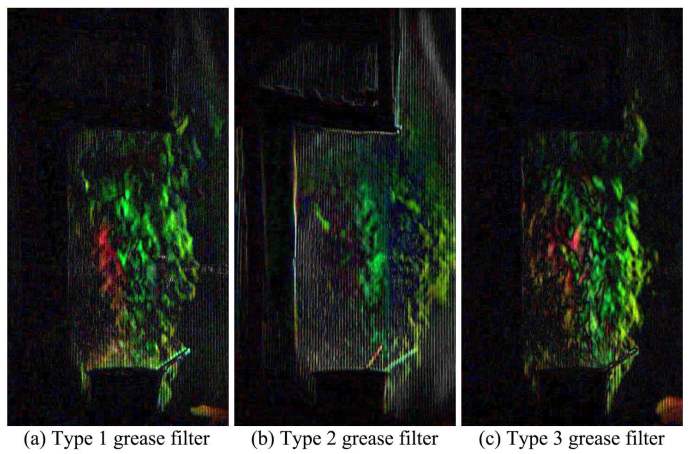

Figure 13. Photo of heat flow with side blocking and puts different type of grease filters on top inlet
Fig. 14 shows photo of heat flow performance under blocking top inlet and puts different grease filters on side inlet of kitchen exhaust hood by using color full-scale Schlieren. Fig. 14(a) shows photo of heat flow with type 1 grease filter. Fig. 14(b) shows photo of heat flow with type 2 grease filter. Fig. 14(c) shows photo of heat flow with type 3 grease filter. The results show that there has no heat flow escaping and the absorbability of different grease filters in sequence are Fig. 14(a) $>$ Fig. 14(c) $>$ Fig. 14(b). In other words, blocks top inlet and puts different grease filters on side inlet of kitchen exhaust hood obtains the best flow field without any escaping waste hot gas and poison gas. Comparing to fig. 15, the noise level also shows that blocking top inlet and putting type 1 grease filters on side inlet of kitchen exhaust hood obtains the smallest noise $65 \mathrm{~dB}$ and best flow behavior.
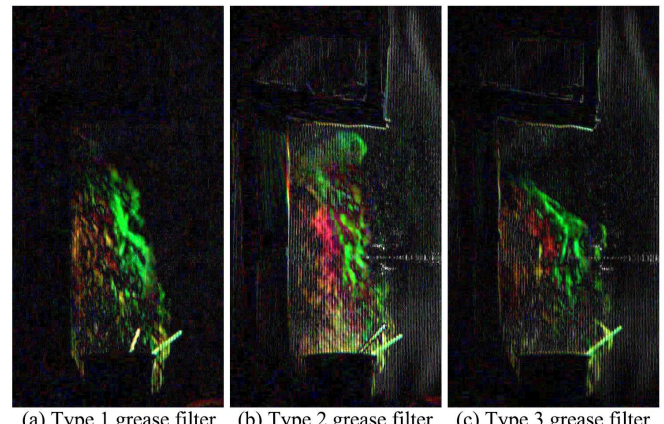

(a) Type 1 grease filter

(b) Type 2 grease filter

(c) Type 3 grease filter

Figure 14. Photo of heat flow blocking top inlet and puts different grease filters on side inlet

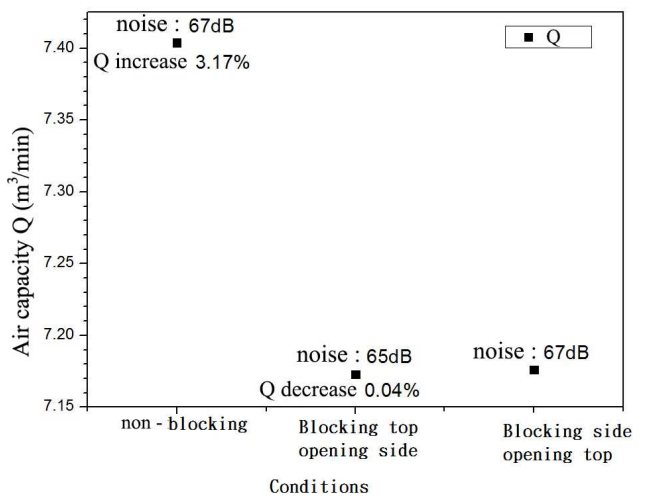

Figure 15. Air capture efficiency and noise values with several masking conditions

The images of heat flow show that using diameter $4 \mathrm{~cm}$ circular opening with top of 44 circular openings, side of 55 circular openings has the best absorbability. From the noise side, the noise which has reduced to ca. $65 \mathrm{~dB}$ is reaching the standards set by CNS. Fig. 15 shows air velocity and noise values with several masking conditions. To investigate the reason, it is because the motor on shelter which has the effect of reducing noise. The result can be further used as the basis of designing the kitchen exhaust hood. That is, add side exhausting method can reduce the motor's power to decrease the harming of noise. According to fig. 16, the higher distance $(Z)$ between stove and exhaust hood the 
more waste hot gas will occur [16]. Reducing the distance between stove and exhaust hood could be exhaust efficiently, but the shorter the distance of $\mathrm{Z}$ will limit chef operation area. This study uses side exhausting method to keep the advantage of short distance $\mathrm{Z}$ and keeping chef operation area.

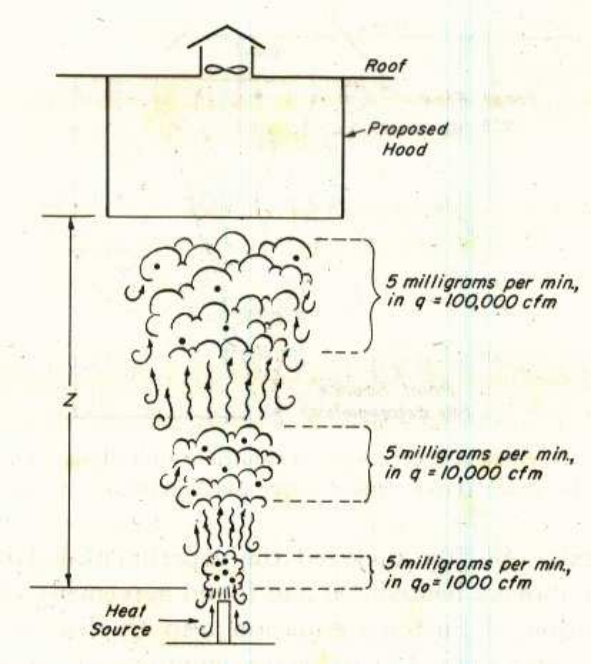

Figure 16. The relationship between distance of $Z$ and waste gas generation [16]

\section{Conclusions}

This study employed color full-scale Schlieren method to visualize kitchen exhaust hood flow behavior. Using optical method can directly exhibit the performance of kitchen exhaust hood. This research also pointed some significant results. Using side exhausting method can reduce the motor's power consumption and fan noise generation. Blocking top inlet and puts type 1 grease filters on side inlet of kitchen exhaust hood obtains the best flow field without any escaping waste hot gas and poison gas.

\section{Acknowledgements}

The authors would like to acknowledge the financial support from the National Science Foundation of Taiwan under Grant No. NSC 102-2622-E-027-002-CC2.

\section{References}

[1] G. S. Settles, Visualizing Full-Scale Ventilation Airflows, ASHRAE Journal, pp. 19-26, 1997.

[2] G. S. Settles, Schlieren and Shadowgraph Imaging in the Great Outdoors, Proceedings of PSFVIP-2, Honolulu, USA, pp.1-14, 1999.
[3] G. S. Settles, Schlieren and Shadowgraph Techniques, Springer, Heidelberg, NY; ISBN 3-540-66155-7, 2001.

[4] Y. C. Hung, C. C. Chen, S. C. Wang, and C. C. Ting, Developing the Modular Background-Oriented Full-Scale Schlieren Technique, Proceedings of ASME 2011 International Mechanical Engineering Congress \& Exposition, IMECE2011, November 11-17, Denver, Colorado, United States, 2011.

[5] C. C. Chen, Y. C. Hung, S. C. Wang, and C. C. Ting, Developing the Color Full-Scale Schlieren Technique for Flow Visualization, Proceedings of ASME 2011 International Mechanical Engineering Congress \& Exposition, IMECE2011, November 11-17, Denver, Colorado, United States, 2011.

[6] C. C. Ting and C. C. Chen, Detection of Gas Leakage Using Micro Color Schlieren Technique, Measurement, 46: 2467-2472,

October, doi:10.1016/j.measurement.2013.04.073, 2013.

[7] C. C. Chen and C. C. Ting, Investigating the Effect of Color Mask on Sensitivity for the Color Schlieren Imaging, International Journal of Engineering and Technology Innovation, 3: (2):114-122, March, 2013.

[8] C. M. Chiang, C. M. Lai, P. C. Chou, and Yen-Yi Li, The influence of an Architectural Design Alternative (transoms) on Indoor Air Environment in Conventional Kitchens in Taiwan, Building and Environment, vol. 35, pp. 579-583, 2000 .

[9] J. Abanto, M. Reggio, Numerical Investigation of the Flow in a Kitchen Hood System, Building and Environment, vol. 41, pp. 288-296, 2006.

[10] C. C. Chen, W. Y. Yan, Y. Y. Wu, and C. C. Ting, Investigating the Optimum Efficiency of Acoustoelectric Conversion Plate Devices, International Journal of Engineering and Technology Innovation, vol. 4, no. 2, 2014, pp. 85-94.

[11] C. C. Chen, D. Y. Tsai, C. C. Ting, and K. Y. Lin, Improvement and Noise reduction for the Active Air Inlet Quick Burner by Using Dispersive Combustion Method, American Journal of Energy and Power Engineering, vol. 1, no. 1,2014 , pp. $1-8$.

[12] T. F. Young, C. C. Chen, Y. S. Liang, Y. H. Pan, K. P. Huang, C. C. Ting, Study on nozzle flow dispersion for noise reduction by using micro color Schlieren technique, International Journal of Modern Physics and Application, vol. 1, no. 1, 2014, pp. 9-14.

[13] Chinese National Standards, CNS 3805, Range Hood.

[14] Chinese National Standards, CNS 3765-31, Safety of House Hold and Similar Electrical Appliances - Part 2: Particular Requirements for Range Hoods.

[15] American Society of Mechanical Engineers, ASTM, D3154-00, 2000.

[16] W. C. L. Hemeon, Plant and Process Ventilation, New York: Industrial Press Inc., 1955. 